Jun Ishii • Makoto Nagano • Takeshi Kujiraoka

Mitsuaki Ishihara · Tohru Egashira - Daisuke Takada

Masahiro Tsuji · Hiroaki Hattori • Mitsuru Emi

\title{
Clinical variant of Tangier disease in Japan: mutation of the ABCA1 gene in hypoalphalipoproteinemia with corneal lipidosis
}

Received: March 1, 2002 / Accepted: March 15, 2002

\begin{abstract}
Despite progress in molecular characterization, specific diagnoses of disorders belonging to a group of inherited hypoalphalipoproteinemias, i.e., apolipoprotein AI deficiency, lecithin-cholesterol acyltransferase deficiency, Tangier disease (TD), and familial high-density lipoprotein (HDL) deficiency, remain difficult on a purely clinical basis. Several TD patients were recently found to be homozygous for mutations in the $A B C A 1$ gene. We have documented here a clinical variant of TD in a Japanese patient who manifested corneal lipidosis and premature coronary artery disease as well as an almost complete absence of HDLcholesterol, by identifying a novel homozygous $A B C A 1$ mutation (R1680W). We propose that patients with apparently isolated HDL deficiency who are found to carry $A B C A 1$ mutations may in fact belong to a category of TD patients whose phenotypic features are only partially expressed, and that a number of hidden clinical variants of TD might exist among other HDL deficiency patients who have escaped correct clinical diagnosis.
\end{abstract}

Key words Tangier disease · $A B C A 1$ gene · HDL deficiency $\cdot$ Hypoalphalipoproteinemia $\cdot$ Corneal lipidosis

\section{Introduction}

Clinical heterogeneity and phenotypic complexity within a group of disorders collectively known as inherited

J. Ishii $\cdot$ M. Tsuji

Division of Internal Medicine, Hokkaido Hospital for Social Health Insurance, Sapporo, Japan

M. Nagano $\cdot$ T. Kujiraoka $\cdot$ M. Ishihara $\cdot$ T. Egashira $\cdot$ H. Hattori Research Department, R \& D Center, BML, Kawagoe, Japan

D. Takada $\cdot$ M. Emi $(\bowtie)$

Department of Molecular Biology, Institute of Gerontology, Nippon Medical School, 1-396 Kosugi-cho, Nakahara-ku, Kawasaki 211-8533, Japan

Tel. +81-44-733-5230; Fax +81-44-733-5192

e-mail: memi@nms.ac.jp

The first two authors contributed equally to the work. hypoalphalipoproteinemia syndromes have hampered their classification into distinct disease entities. From a clinical standpoint, the term "inherited hypoalphalipoproteinemia" can apply to apolipoprotein AI (apoAI) deficiency, lecithincholesterol acyltransferase (LCAT) deficiency, Tangier disease (TD), or so-called familial high-density lipoprotein (HDL) deficiency (Assmann et al. 1995). Despite some progress in molecular characterization, specific diagnoses of these disorders remain difficult because of their phenotypic spectra overlap and because the penetrance of some symptoms is age related.

Mutation in $A B C A 1$, a gene mapping to 9q31 and encoding an ATP-binding cassette transporter, confers susceptibility to TD, a recessive disease (Bodzioch et al. 1999; Brooks-Wilson et al. 1999; Rust et al. 1999). It appears that $A B C A 1$ mutations are detected more frequently in TD patients when strict clinical criteria are applied to the selection of test subjects. Some researchers believe that mutations in this gene also predispose carriers to an isolated clinical feature called familial HDL deficiency; however, some controversy exists about the molecular basis of the latter disorder. Three possibilities have been raised: (1) homozygous mutations of the $A B C A 1$ gene are responsible for HDL deficiency in some affected families (Huang et al. 2001; Nishida et al. 2002); (2) heterozygous $A B C A 1$ mutations appear to be the predisposing elements for some patients diagnosed with familial HDL deficiency (Brooks-Wilson et al. 1999; Marcil et al. 1999); and (3) yet another putative locus on chromosome $1 \mathrm{q}$, close to apolipoprotein AII (apoAII), may be linked to familial HDL deficiency in some affected families. The low penetrance of HDL deficiency syndrome, the fact that it may share some phenotypic features with TD, and the possible genetic heterogeneity of HDL deficiency syndrome tend to confound diagnostic efforts in clinical settings.

Pathognomonic hallmarks of typical TD include a recessive mode of inheritance, HDL deficiency, enlarged orange tonsils, hepatosplenomegaly, peripheral neuropathy, and, frequently, premature onset of coronary artery disease (CAD), whereas familial HDL deficiency is diagnosed solely on the basis of absence or marked reduction of HDL 
cholesterol (HDL-C) in plasma. Here we describe a clinical variant of TD in a Japanese patient with HDL deficiency and corneal lipidosis, who carries mutations of $A B C A 1$ in both alleles.

\section{Subjects and methods}

The proband was a 48-year-old Japanese male $(159 \mathrm{~cm}$, $61 \mathrm{~kg}$ ) who was being followed clinically by one of us (M.T.) at the outpatient clinic of Hokkaido Hospital for Social Health Insurance. He exhibited severe HDL deficiency, i.e., an almost complete absence of HDL-c and apoAI in plasma, in addition to other findings described in the following paragraphs. Consanguinity was noted, because his parents were first cousins.

Although he had no pathognomonic lesions of TD such as hepato-splenomegaly or peripheral neuropathy, we extended our clinical examination to the patient's whole body and tested him for mutation of the $A B C A 1$ gene, in view of proposals by Assmann (Rust et al. 1999) and Schmitz (Bodzioch et al. 1999) that an $A B C A 1$ mutation can be a useful diagnostic marker for incompletely expressed TD. After obtaining informed consent, we examined genomic DNA from the patient and members of his family by direct sequencing of the entire coding region and exon-intron boundaries of $A B C A 1$, according to procedures described previously (Rust et al. 1999). Briefly, genomic DNA was extracted from peripheral leukocytes, and all 50 exons, including exon-intron junctions, were individually amplified by polymerase chain reaction (PCR) with primers designed according to archived sequences (Accession numbers AF165281 and AF275948; Santamarina-Fojo et al. 2000). Each PCR product was sequenced directly on both strands, as described by Wu et al. (2000). We tested for the observed R1680W mutation in the proband and relatives using the PCR-restriction fragment length polymorphism (RFLP) method, by amplifying a 351-bp fragment of exon 37 with primers $5^{\prime}$-TTGACTGTTGCCCCTTATCTA-3' and 5'-ATGCCCCTGCCAACTTTACC-3' and digesting the product with BsrBI. Samples were electrophoresed in a 3\% agarose gel and the bands were visualized with ethidium bromide.

\section{Results}

The patient $(\mathrm{P})$ was found to be homozygous for a C-to-T transition at nucleotide 5038 (codon 1680, exon 37) of $A B C A 1$, which would result in substitution of Trp for Arg $(1680 \mathrm{~W})$. The patient's three sons (S1, S2, S3) were all heterozygous for this substitution. Figure 1 shows PCRRFLP diagnosis of these four family members. We did not detect the substitution in any of 192 control chromosomes from unrelated Japanese individuals. However, we did note in our patient a frequent polymorphism, $\mathrm{G} \rightarrow \mathrm{A}$ at 4760 , that

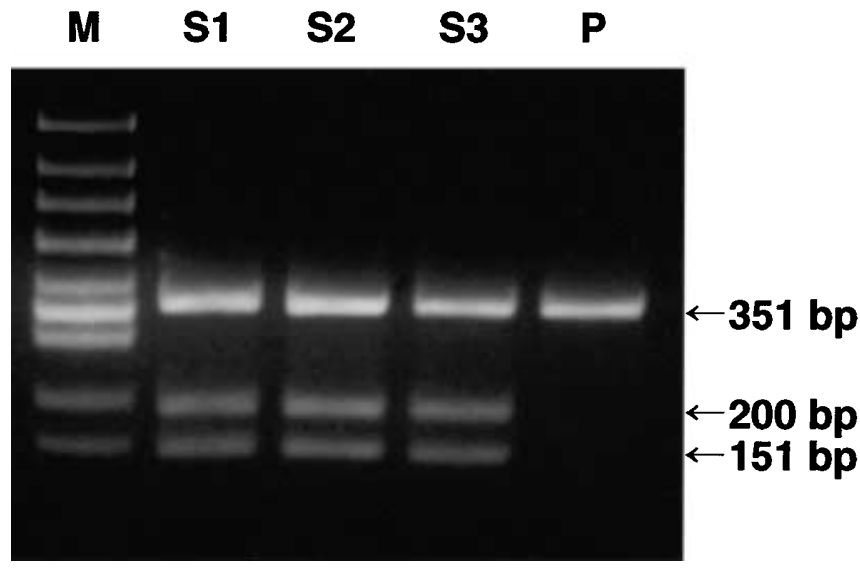

Fig. 1. Detection of the R1680W mutation in the proband's family by polymerase chain reaction (PCR)-restriction fragment length polymorphism. PCR products from exon 37 of the $A B C A 1$ gene were digested with $B s r \mathrm{BI}$ for $5 \mathrm{~h}$ at $37^{\circ} \mathrm{C}$. The substitution of $\mathrm{C}$ to $\mathrm{T}$ at nucleotide 5038 creates a cleavage site (GAGCGG) for this endonuclease, yielding fragments of $151 \mathrm{bp}$ and $200 \mathrm{bp}$ from a 351-bp portion of exon 37. $P$, Proband; $S 1, S 2$, and $S 3$, three children of the proband; $M$, size marker

Table 1. Lipid profiles in a Tangier patient and his family members

\begin{tabular}{lcccc}
\hline Variables & P & S1 & S2 & S3 \\
\hline Age (years) & 48 & 14 & 11 & 5 \\
TC (mmol/l) & 2.49 & 4.33 & 4.74 & 4.53 \\
TG (mmol/l) & 1.94 & 0.42 & 1.20 & 0.35 \\
LDL-C (mmol/l) & 1.47 & 2.84 & 3.23 & 2.97 \\
HDL-C (mmol/l) & 0.13 & 1.30 & 0.96 & 1.40 \\
ApoAI (mg/dl) & 7.0 & 122 & 113 & 126 \\
ApoAII (mg/dl) & 8.8 & 32.7 & 32.0 & 37.2 \\
ApoB (mg/dl) & 90 & 81 & 111 & 126 \\
ApoCII (mg/dl) & 3.8 & 2.9 & 2.9 & 2.0 \\
ApoCII (mg/dl) & 6.5 & 6.3 & 7.0 & 4.5 \\
ApoE (mg/dl) & 2.4 & 3.5 & 3.5 & 3.0 \\
\hline
\end{tabular}

TC, Total cholesterol; TG, triglyceride; LDL-C, low-density lipoprotein-cholesterol; HDL-C, high-density lipoprotein-cholesterol; Apo, apolipoprotein

had been described previously in the Japanese population (Iida et al. 2001); the proband was homozygous for the minor allele. He carried no mutations in his apoAI or $L C A T$ genes. The proband, but none of his children with heterozygosity for the $A B C A 1$ mutation, displayed marked reduction in plasma levels of HDL-c, apoAI, and apoAII (Table 1).

On closer examination of the proband using coronary angiography and computerized tomography (Fig. 2), we observed bilateral corneal lipidosis and progressive occlusion of the anterior descending (\#7) and circumflex (\#11) regions of the left coronary artery (Fig. 2B). Hepatosplenomegaly and peripheral neuropathy were absent (Fig. 2). $\mathrm{He}$ had undergone tonsillectomy in childhood. Thus, molecular testing of the $A B C A 1$ gene led us to a diagnosis of TD in a patient who manifested atypical symptoms of that disease and might otherwise have been diagnosed merely with isolated HDL deficiency. 
Fig. 2. Intensive clinical examination of the proband, demonstrating narrowing of two portions of the right coronary artery $(\mathbf{A})$, left coronary artery $(\mathbf{B})$, corneal lipidosis $(\mathbf{C})$, and absence of hepatosplenomegaly $(\mathbf{D})$

\section{A. Right coronary artery}

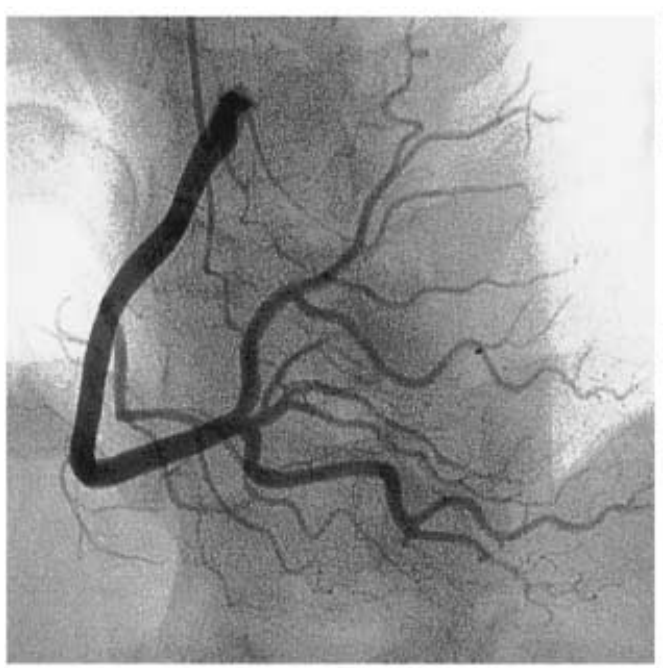

\section{B. Left coronary artery}

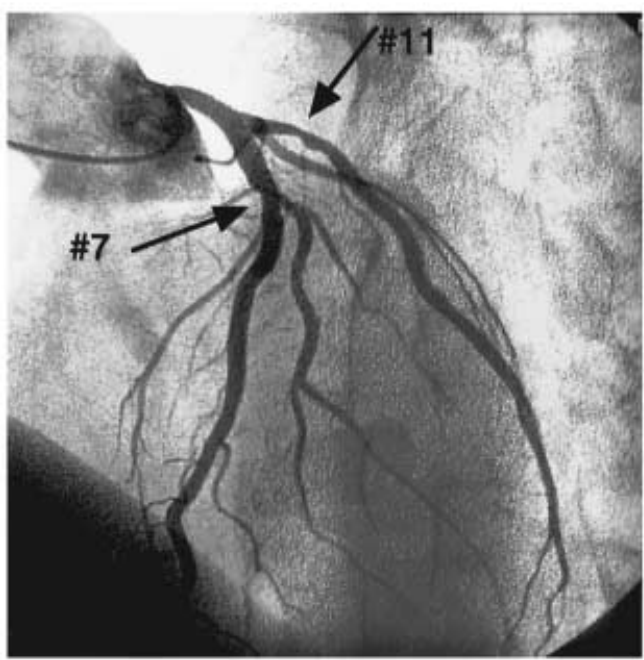

\section{Corneal lipidosis}

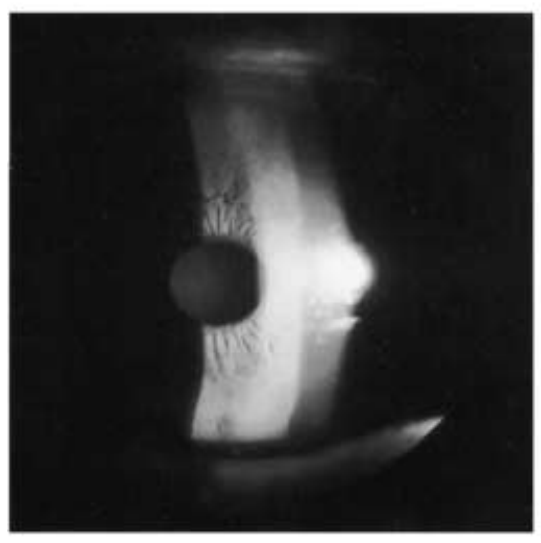

\section{Abdominal computed tomography}

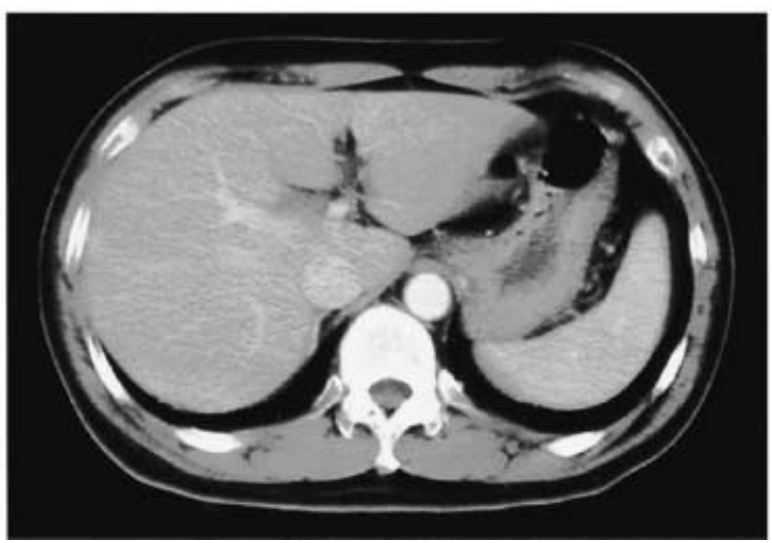

\section{Discussion}

Germline mutation in our proband had occurred in the intracellular loop of the second half of six membranespanning domains, where amino-acid sequence is highly conserved among species. Most of the germline missense mutations of $A B C A 1$ reported in patients with typical TD have occurred within the first extracellular loop of the first half of the membrane-spanning domain and the nucleotidebinding fold (Bodzioch et al. 1999; Brooks-Wilson et al. 1999). Functional consequences of mutations occurring in different regions of the predicted protein might well relate to the phenotypic differences between our patient and carriers of typical TD.

An autosomal recessive mode of inheritance, a severe deficiency or absence of HDL in plasma, and an accumulation of cholesterol in many tissues characterize the clinical syndrome in TD patients who are homozygous for mutation of the $A B C A 1$ gene. Defects in this gene lead to the accumulation of cholesteryl ester in cells as a result of abnormal cholesterol efflux, normally the first step in reverse cholesterol transport (Orso et al. 2000). We suspect that apparent
HDL deficiency patients in Japan who carry $A B C A 1$ germline mutations (Huang et al. 2001; Nishida et al. 2002) may in fact belong to a category of TD patients whose phenotypic features are only partially expressed.

We have demonstrated that the presence of a germline $A B C A 1$ mutation can be a reliable diagnostic sign for TD. The results described here signal the possibility that many hidden clinical variants of TD may exist among HDLdeficient patients who might have escaped correct clinical diagnosis. Our work underscores the usefulness and importance of molecular methods for achieving accurate diagnoses of patients with HDL deficiency, because these inherited syndromes may predispose carriers to lifethreatening, premature CAD.

\section{References}

Assmann G, von Eckardstein A, Brewer HB (1995) Familial high density lipoprotein deficiency: Tangier disease. In: Scriver CR, Beaudet AL, Sly WS, Valle D (eds) The metabolic and molecular bases of inherited disease. McGraw-Hill, New York, pp 20532072 
Bodzioch M, Orso E, Klucken J, Langmann T, Bottcher A, Diederich W, Drobnik W, Barlage S, Buchler C, Porsch-Ozcurumez M, Kaminski WE, Hahmann HW, Oette K, Rothe G, Aslanidis C, Lackner KJ, Schmitz G (1999) The gene encoding ATP-binding cassette transporter 1 is mutated in Tangier disease. Nat Genet 22:347-351

Brooks-Wilson A, Marcial M, Clee SM, Zhang L-H, Roomp K, van Dam M, Yu L, Brewer C, Collins JA, Molhuizen HOF, Louber O, Ouelette BFF, Fichter K, Ashbourne-Excoffon KJD, Sensen CW, Scherer S, Mott S, Denis M, Martindale D, Frohlich J, Morgan K, Koop B, Pimstone S, Kastelein JJP, Genest J, Hayden MR (1999) Mutations in $A B C A 1$ in Tangier disease and familial high-density lipoprotein deficiency. Nat Genet 22:336-345

Huang W, Moriyama K, Koga T, Hua H, Ageta M, Kawabata $\mathrm{S}$, Mawatari K, Imamura $\mathrm{T}$, Eto $\mathrm{T}$, Kawamura $\mathrm{M}$, Teramoto $\mathrm{T}$, Sasaki J (2001) Novel mutations in $A B C A 1$ gene in Japanese patients with Tangier disease and familial high density lipoprotein deficiency with coronary heart disease. Biochim Biophys Acta 1537:71-78

Iida A, Saito S, Sekine A, Kitamura Y, Kondo K, Mishima C, Osawa S, Harigae S, Nakamura Y (2001) High-density single-nucleotide polymorphism (SNP) map of the 150-kb region corresponding to the human ATP-binding cassette transporter A1 ( $A B C A 1)$ gene. J Hum Genet 46:522-528

Marcil M, Brooks-Wilson A, Clee SM, Roomp K, Zhang LH, Collins JA, Loubser O, Ouelette BFF, Sensen CW, Fichter K, Yu L, Mott S, Denis M, Martindale D, Koop B, Pimstone S, Kastelein JJP, Genest J, Hyden MR (1999) Familial HDL deficiency with defective cholesterol efflux is caused by mutations in the $A B C A 1$ gene (CERP). Lancet 354:1341-1346
Nishida Y, Hirano K, Tsukamoto K, Nagano M, Ikegami C, Roomp K, Ishihara M, Sakane N, Zhang Z, Tsuji K, Matsuyama A, Ohama T, Matsuura F, Hattori H, Wellington C, Yoshida Y, Misugi S, Hayden MR, Egashira T, Yamashita S, Matsuzawa Y (2002) Expression and functional analyses of disease-associated novel mutations of ATPbinding cassette transporter-1 $(A B C A 1)$ in Japanese patients with high density lipoprotein deficiency. Biochem Biophys Res Commun 290:713-721

Orso E, Broccardo C, Kaminski WE, Bottcher A, Liebisch G, Drobnik W, Gotz A, Chambenoit O, Diederich W, Langmann T, Spruss T, Luciani MF, Rothe G, Lackner K, Chimini G, Schmitz G (2000) Transport of lipids from Golgi to plasma membrane is defective in Tangier disease patients and ABC1-deficient mice. Nat Genet 24:192-196

Rust S, Roiser M, Funke H, Real J, Amoura Z, Piette J-C, Deleuze J-F, Brewer HB, Duverger N, Denefle P, Assmann G (1999) Tangier disease is caused by mutations in the gene encoding ATP-binding cassette transporter 1. Nat Genet 22:352-355

Santamarina-Fojo S, Peterson K, Knapper C, Qiu Y, Freeman L, Cheng J-F, Osorio J, Remaley A, Yang X-P, Haudenschild C, Prades C, Chimini G, Blackmon E, Francois T, Duverger N, Rubin EM, Rosier M, Denefle P, Fredrickson D, Brewer BJ (2000) Complete genomic sequence of the human $A B C A 1$ gene: analysis of the human and mouse ATP-binding cassette A promoter. Proc Natl Acad Sci USA 7978-7992

Wu LL, Hopkins PN, Xin Y, Stephenson SH, Williams RR, Nobe Y, Kajita M, Nakajima T, Emi M (2000) Co-segregation of elevated LDL with a novel mutation (D92K) of the LDL receptor in a kindred with multiple lipoprotein abnormalities. J Hum Genet 45: 154-158 